\title{
Effects of Variable Thermal Conductivity and Chemical Reaction on Steady Mixed Convection Boundary Layer Flow with Heat and Mass Transfer Inside a Cone due to a Point Sink
}

\author{
V. Bisht ${ }^{1+}$, M. Kumar ${ }^{2}$ and Z. Uddin ${ }^{3}$ \\ ${ }^{I}$ Department of Mathematics, SRMS, CET, Bareilly -243202, UP, India \\ ${ }^{2}$ Department of Mathematics, GBPUAT, Pantnagar -263145, Uttarakhand, India \\ ${ }^{3}$ Department of Applied Sciences, ITM University, Sector 23-A, Gurgaon, 122017 \\ $\dagger$ Corresponding Author Email: vandanabisht7@gmail.com
}

(Received August 19, 2009; accepted April 2, 2010)

\begin{abstract}
The steady incompressible mixed convection boundary layer flow with variable fluid properties and mass transfer inside a cone due to a point sink at the vertex of the cone have been investigated. The fluid viscosity and thermal conductivity have been assumed to be temperature dependent. The governing fluid flow equations with boundary conditions have been transformed into set of coupled ordinary differential equations with the help of similarity transformations and solved Runge-Kutta method with shooting technique. The effects of Schmidt number, variable thermal conductivity parameter, mixed convection parameter, buoyancy parameter and chemical reaction parameter on velocity distribution, temperature distribution, concentration distribution, heat transfer rate and coefficient of skinfriction have been investigated. It is observed that concentration decreases with increasing Schmidt number and temperature increases with increasing values of thermal conductivity parameter. Also with increasing values of mixed convection parameter, velocity, temperature and concentration decreases. The present study is relevant in conical nozzle and diffuser flow problems exist in petroleum and chemical industries.
\end{abstract}

Keywords: Forced convection, Point sink, Variable viscosity, Heat transfer, Skin friction.

\section{NOMENCLATURE}

Constant

Concentration of fluid

$\mathrm{C}_{\mathrm{w}} \quad$ Concentration at the wall

$\mathrm{C}_{\infty} \quad$ Concentration of fluid at $(\eta \rightarrow \infty)$

$\mathrm{C}_{f} \quad$ Surface friction

$\mathrm{C}_{p} \quad$ Specific heat at constant pressure

D Mass diffusion coefficient

f Dimensionless stream function

$\mathrm{F}=\mathrm{f}^{\prime} \quad$ Dimensionless velocity component

$\mathrm{F}_{\mathrm{w}}^{\prime} \quad$ Skin friction parameter

g Acceleration due to gravity

G Dimensionless temperature

$\mathrm{Ge} \quad$ Viscosity variation parameter

GrT Thermal Grashof number

$\mathrm{Gr}_{\mathrm{C}} \quad$ Mass Grashof number

$\mathrm{G}_{\mathrm{w}}^{\prime} \quad$ Heat transfer rate

$\mathrm{H} \quad$ Dimensionless concentration

$\mathrm{H}_{\mathrm{w}}^{\prime} \quad$ Mass transfer rate

$\mathrm{k} \quad$ Thermal conductivity of fluid

$\mathrm{k}_{\mathrm{c}} \quad$ Chemical reaction parameter

$\mathrm{k}_{1} \quad$ Dimensionless chemical reaction parameter
Pr Prandtl number

$\mathrm{Re}_{r} \quad$ local Reynold's number

Sc Schmidt number

$\mathrm{Sh}_{\mathrm{r}} \quad$ Sherwood number

$\mathrm{T}$ Temperature of the fluid

$\mathrm{T}_{w} \quad$ Temperature at the wall $(\eta=0)$

$\mathrm{T}_{\infty} \quad$ Temperature of fluid in the free stream $(\eta \rightarrow \infty)$

$\mathrm{T}_{e} \quad$ Temperature of the fluid at the edge of boundary layer

$\mathrm{u} \quad$ Velocity component of fluid along r-direction

U Inviscid fluid velocity

$\mathrm{w}$ Velocity component of fluid along z-direction

$\alpha \quad$ Thermal diffusivity

$\beta_{\mathrm{T}} \quad$ Coefficient of thermal expansion

$\beta_{C} \quad$ Coefficient of expansion with concentration

$\varepsilon \quad$ Variable thermal conductivity parameter

$\mu \quad$ Coefficient of thermal expansion

$\lambda$ Buoyancy force due to thermal diffusion

$\delta \quad$ Buoyancy force due to mass diffusion

$\boldsymbol{v}$ Kinematic viscosity

$\rho \quad$ Density of fluid

$\sigma \quad$ Electrical conductivity of the fluid 
$\mathrm{k}^{*} \quad$ Variable thermal conductivity

N Relative Buoyancy parameter

$\mathrm{Nu}_{r} \quad$ Nusselt number

\section{INTRODUCTION}

The steady, laminar, axi-symmetric, mixed convective boundary layer flow of a viscous incompressible fluid with heat and mass transfer, chemical reaction and variable fluid properties inside a cone due to a point sink has gained considerable importance in many branches of engineering. The effect of heat transfer in axi-symmetric flow, inside a cone due to a point sink, in the absence of magnetic field has been studied by Rosenhead (1963) using similarity transformations. A series solution for the converging motion of the viscous flow inside a cone under some restricted conditions on the potential flow has been studied by Ackerberg (1965). The steady MHD laminar axi-symmetric boundary-layer flow in a cone due to a point sink with an applied magnetic field, heat and mass transfer have been investigated by Takhar (1986). The unsteady MHD forced axi-symmetric flow inside a cone due to a point sink has been studied by Eswara and Roy (2000). Eswara and Bommaiah (2004) investigated the influence of variation of viscosity with temperature on axi-symmetric flow inside a cone due to a point sink. In the previous studies with axi-symmetric flow inside a cone due to a point sink, the thermal conductivity of fluid was assumed to be constant. However, it is known that thermal conductivity of fluid may also be change with temperature. Hence, like other thermophysical properties, temperature-dependent thermal conductivity also plays a vital role in surface friction and heat transfer rate near the wall. The effect of variable thermal conductivity along a stretching sheet with MHD flow and in the presence of heat source or sink has been studied by Sharma and Singh (2008). Seddeek and Salem (2005) investigated the effects of heat and mass transfer on stretching surface with variable viscosity and variable thermal diffusivity. The effects of variable thermal conductivity and variable viscosity on steady free convective heat transfer flow process along an isothermal vertical plate in the presence of heat sink has been presented by Mahanti and Gaur (2009). The effect of chemical reaction in a heat and mass transfer flow process along an vertical surface has been discussed by Muthucumaraswamy (2002). Ibrahim, Elaiw and Bakr (2008) found analytical solutions for heat and mass transfer flow of Newtonian fluid along a vertical permeable surface in the presence of radiation and also with homogeneous first order chemical reaction. Due to the numerous applications of chemical reaction effect, e.g. in chemical engineering, in polymer production and in manufacturing of ceramics etc. this effect is also considered in the present study.

The aim of this study to investigate the effect of variable thermal conductivity and chemical reaction on steady laminar axi-symmetric mixed convection boundary layer fluid flow with heat and mass transfer, inside a infinite right circular cone due to a point sink. The governing coupled non-linear equations with twopoint boundary conditions have been solved using with Runge-Kutta method with shooting technique. $\eta \quad$ Transformed similarity variable

$\boldsymbol{\psi}$ Dimensionless stream function

\section{FORMULATION}

The steady, laminar, axi-symmetric, mixed convection boundary layer fluid flow inside a semi- infinite right circular cone, with variable thermal conductivity and in the presence of chemical reaction has been made. The cone has a hole at the apex, which is regarded as a three dimensional point sink. The cone has been taken semi infinite so that it can be regarded as independent of length scale $r$. The physical model and coordinate system have been shown in Fig. 1.

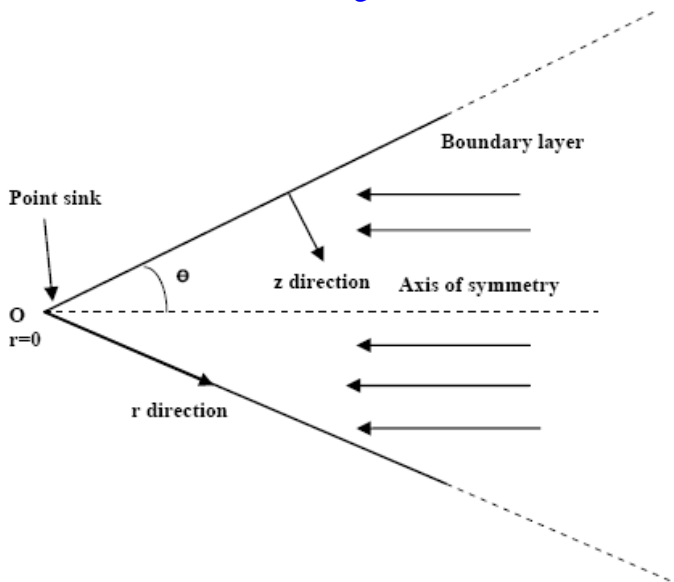

Fig. 1. The physical model and coordinate system

All fluid properties are assumed to be constant except fluid viscosity and thermal conductivity. The boundary layer equations are:

Equation of continuity,

$\frac{\partial(\mathrm{ru})}{\partial \mathrm{r}}+\frac{\partial(\mathrm{rw})}{\partial \mathrm{z}}=0$

Equation of momentum,

$\rho\left(u \frac{\partial u}{\partial r}+w \frac{\partial u}{\partial z}\right)=-\frac{\partial P}{\partial r}+\frac{\partial}{\partial z}\left(\mu \frac{\partial u}{\partial z}\right)+g \beta_{t} \rho\left(T-T_{\infty}\right)+$ $g \beta_{c} \rho\left(C-C_{\infty}\right)$

Equation of heat transfer,

$\rho C_{p}\left(u \frac{\partial T}{\partial r}+w \frac{\partial T}{\partial z}\right)=\frac{\partial}{\partial z}\left(k \frac{\partial T}{\partial z}\right)+u \frac{\partial P}{\partial r}$

Equation of mass transfer,

$\mathrm{u} \frac{\partial \mathrm{C}}{\partial \mathrm{r}}+\mathrm{w} \frac{\partial \mathrm{C}}{\partial \mathrm{z}}=\mathrm{D} \frac{\partial^{2} \mathrm{C}}{\partial \mathrm{z}^{2}}-\mathrm{k}_{\mathrm{l}}\left(\mathrm{C}-\mathrm{C}_{\infty}\right)$

where

$\left(-\frac{1}{\rho}\right) \frac{\partial \mathrm{P}}{\partial \mathrm{r}}=\mathrm{U} \frac{\partial \mathrm{U}}{\partial \mathrm{r}} \quad$ and $\quad \mathrm{U}=-\frac{\mathrm{m}}{\mathrm{r}^{2}}, \mathrm{~m}>0$

The initial and boundary conditions are,

$\mathrm{u}(\mathrm{r}, 0)=0, \mathrm{w}(\mathrm{r}, 0)=0, \mathrm{~T}(\mathrm{r}, 0)=\mathrm{T}_{\mathrm{w}}, \mathrm{C}(\mathrm{r}, 0)=\mathrm{C}_{\mathrm{w}}, \quad$ at $\mathrm{z}=0$

$\mathrm{u}(\mathrm{r}, \infty)=\mathrm{U}, \quad \mathrm{T}(\mathrm{r}, \infty)=\mathrm{T}_{\infty}, \mathrm{C}(\mathrm{r}, \infty)=\mathrm{C}_{\infty}, \quad$ as $\mathrm{z} \rightarrow \infty$

The viscosity and thermal conductivity of fluid are considered to vary with temperature as given below,

$\mu=\frac{\mu_{\infty}}{1+\beta\left(T-T_{\infty}\right)}$ 
$\mathrm{k}=\mathrm{k}^{*}(1+\varepsilon \theta)$

Here $\quad \beta=-\frac{1}{T_{e}-T_{\infty}}$ and $G e=\frac{T_{e}-T_{\infty}}{T_{w}-T_{\infty}}=-\frac{1}{\beta\left(T_{w}-T_{\infty}\right)}$ Applying following transformations to Eqs. (1) to (5),

$\eta=\left(\frac{m}{2 v r^{3}}\right)^{\frac{1}{2}} z, \psi(r, z)=-(2 m v r)^{\frac{1}{2}} f(\eta)$

$\mathrm{u}=\frac{1}{\mathrm{r}} \frac{\partial \psi}{\partial \mathrm{z}}, \quad \mathrm{w}=-\frac{1}{\mathrm{r}} \frac{\partial \psi}{\partial \mathrm{r}}$

$G(\eta)=\frac{T-T_{\infty}}{T_{w}-T_{\infty}}, H(\eta)=\frac{C-C_{\infty}}{C_{w}-C_{\infty}}$

$\operatorname{Pr}=\frac{v}{\alpha}, v=\frac{\mu_{\infty}}{\rho}, u=U F(\eta)$

$\mathrm{w}=\left(\frac{\mathrm{mv}}{2 \mathrm{r}^{3}}\right)^{1 / 2}\{\mathrm{f}-3 \eta \mathrm{F}\}$

$\mathrm{f}=\int_{0}^{\eta} \mathrm{Fd} \eta, \mathrm{F}=\mathrm{f}^{\prime}, \mu=\frac{\mu_{\infty}}{1-\frac{\mathrm{G}}{\mathrm{Ge}}}$

$\operatorname{Re}_{\mathrm{r}}=\frac{\mathrm{m}}{v \mathrm{r}}, \quad \mathrm{k}_{\mathrm{c}}=\frac{2 \mathrm{k}_{\mathrm{l}} \mathrm{r}^{3}}{\mathrm{~m}}$

$\mathrm{Gr}_{\mathrm{T}}=\frac{2 \mathrm{~g} \beta_{\mathrm{T}}\left(\mathrm{T}_{\mathrm{w}}-\mathrm{T}_{\infty}\right) \mathrm{r}^{5}}{\mathrm{~m}^{2}}, \mathrm{Gr}_{\mathrm{C}}=\frac{2 \mathrm{~g} \beta_{\mathrm{C}}\left(\mathrm{C}_{\mathrm{w}}-\mathrm{C}_{\infty}\right) \mathrm{r}^{5}}{\mathrm{~m}^{2}}$

$\lambda=\frac{\mathrm{Gr}_{\mathrm{T}}}{\mathrm{Re}_{\mathrm{r}}^{2}}, \delta=\frac{\mathrm{Gr}_{\mathrm{C}}}{\mathrm{Re}_{\mathrm{r}}^{2}}$ and

$\mathrm{N}=\frac{\delta}{\lambda}=\frac{\beta_{\mathrm{C}}\left(\mathrm{C}_{\mathrm{w}}-\mathrm{C}_{\infty}\right)}{\beta_{\mathrm{T}}\left(\mathrm{T}_{\mathrm{w}}-\mathrm{T}_{\infty}\right)}$

The equation of continuity is identically satisfied with the above transformations and Eqs. (2) - (4) reduce to

$\mathrm{F}^{\prime \prime}+\frac{\mathrm{F}^{\prime} \mathrm{G}^{\prime}}{\mathrm{Ge}\left(1-\frac{\mathrm{G}}{\mathrm{Ge}}\right)}+\left[4\left(1-\mathrm{F}^{2}\right)-\mathrm{fF}^{\prime}-\lambda(\mathrm{G}+\mathrm{NH})\right](1-$

$\left.\frac{\mathrm{G}}{\mathrm{Ge}}\right)=0$

$(1+\varepsilon G) G^{\prime \prime}+\varepsilon G^{\prime 2}-\operatorname{Pr} G^{\prime} f=0$

$\mathrm{H}^{\prime \prime}-\mathrm{Sc} \mathrm{fH}^{\prime}-\mathrm{k}_{\mathrm{c}} \mathrm{Sc} \mathrm{H}=0$

and prime (') denotes the derivative with respect to $\eta$. The boundary conditions (5) are transformed into,

$\mathrm{F}=0, \quad \mathrm{G}=1, \mathrm{H}=1 \quad$ at $\eta=0$

$\mathrm{F}=1, \quad \mathrm{G}=0, \quad \mathrm{H}=0 \quad$ as $\eta \rightarrow \infty$

The boundary layer parameters surface friction $\left(\mathrm{C}_{\mathrm{f}}\right)$ and Nusselt number $\left(\mathrm{Nu}_{\mathrm{r}}\right)$ are defined as

$$
\mathrm{c}_{\mathrm{f}}=\frac{2 \tau_{\mathrm{W}}}{\rho \mathrm{U}^{2}}=2^{1 / 2}\left(\operatorname{Re}_{\mathrm{r}}\right)^{-\frac{1}{2}}\left[\frac{1}{\left(1-\frac{\mathrm{G}}{\mathrm{Ge}}\right)}\right] \mathrm{F}_{\mathrm{w}}{ }
$$

where

$\tau_{\mathrm{w}}=-\mu\left(\frac{\partial \mathrm{u}}{\partial \mathrm{z}}\right)_{\mathrm{w}}$

and

$\mathrm{Nu}_{\mathrm{r}}=\frac{\mathrm{rq}_{\mathrm{w}}}{\mathrm{k}\left(\mathrm{T}_{\mathrm{w}}-\mathrm{T}_{\infty}\right)}=-2^{-1 / 2} \operatorname{Re}_{\mathrm{r}}^{1 / 2} \mathrm{G}_{\mathrm{w}}^{\prime}$

where

$\mathrm{q}_{\mathrm{w}}=-\mathrm{k}\left(\frac{\partial \mathrm{T}}{\partial \mathrm{z}}\right)_{\mathrm{w}}$

Similarly, the local mass flux in terms of Sherwood number can be expressed as

$\mathrm{Sh}_{\mathrm{r}}=\frac{\mathrm{rm}_{\mathrm{w}}}{\rho \mathrm{D}\left(\mathrm{C}_{\mathrm{w}}-\mathrm{C}_{\infty}\right)}=-2^{-1 / 2} \operatorname{Re}_{\mathrm{r}}^{1 / 2} \mathrm{H}_{\mathrm{w}}^{\prime}$ $\mathrm{m}_{\mathrm{w}}=-\rho \mathrm{D}\left(\frac{\partial \mathrm{C}}{\partial \mathrm{z}}\right)_{\mathrm{w}}$

Here $\tau_{\mathrm{w}}, \mathrm{q}_{\mathrm{w}}$ and $\mathrm{m}_{\mathrm{w}}$ are shear stress, heat transfer rate and mass transfer rate at the wall respectively.

\section{Particular Cases}

In the absence of variable thermal conductivity parameter, mass transfer and chemical reaction parameter, i.e. for $\varepsilon=0$ and $k_{c}=0$, the results of present paper are reduced to those obtained by Eswara and Bommaiah (2004). Hence results are good agreement with Eswara and Bommaiah (2004). In the absence of heat and mass transfer, chemical reaction and for constant thermal conductivity case the present study reduces to the study given by Roseanhead (1963), who studied only the momentum transfer inside the boundary layer with constant viscosity.

\section{RESULTS AND DISCUSSION}

The set of transformed coupled Eqs. (7) - (9) with boundary conditions given by Eq. (10) are solved with the help of Runge- Kutta method with shooting technique with a systematic guessing of $F^{\prime}(0)$ and $G^{\prime}(0)$ and $\mathrm{H}^{\prime}(0)$. The computations have been carried out with $\Delta \eta=0.01, \eta(\infty)=4$ and for different values of the parameters $\mathrm{Sc}, \mathrm{k}_{\mathrm{c}}, \varepsilon, \lambda$ and $\mathrm{N}$. The fluid considered in the study is air, which contains most of the gases and for which $\operatorname{Pr}=0.7$. The value of viscosity variation parameter is; $\mathrm{Ge}>0$ for gases and $\mathrm{Ge}<0$ for liquids. Here for the considered case the value of Ge is taken as 2 and $\operatorname{Pr}=0.7$.

Figure 2 presents the effect of Schmidt number (Sc) on concentration $(\mathrm{H})$. It shows that magnitude of concentration decreases with increasing values of Sc. In Fig. 3 it has been seen that magnitude of temperature increases with increasing values of thermal conductivity parameter $(\varepsilon)$.

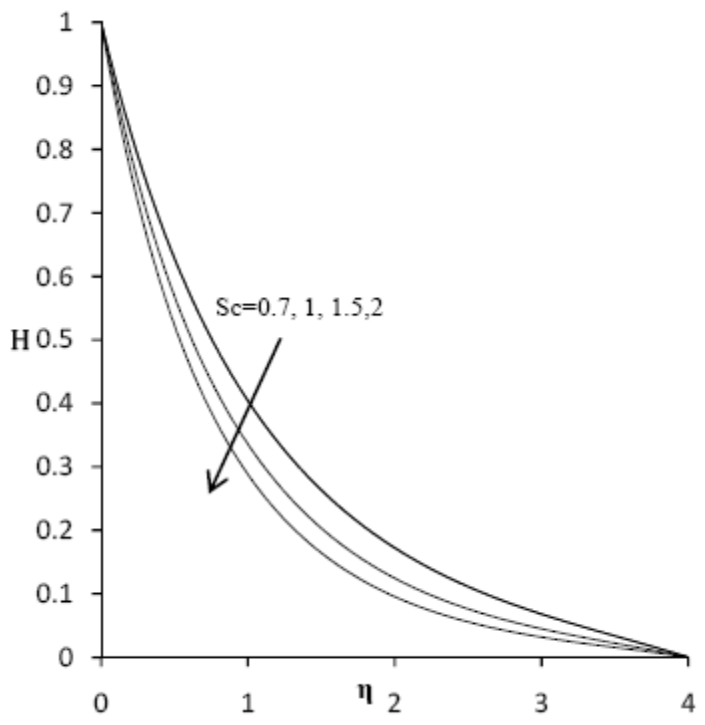

Fig. 2. Concentration profile with $\mathrm{Sc}\left(\operatorname{Pr}=0.7, \mathrm{k}_{\mathrm{c}}=1\right.$, $\varepsilon=1, \mathrm{~N}=1, \lambda=1)$

where 


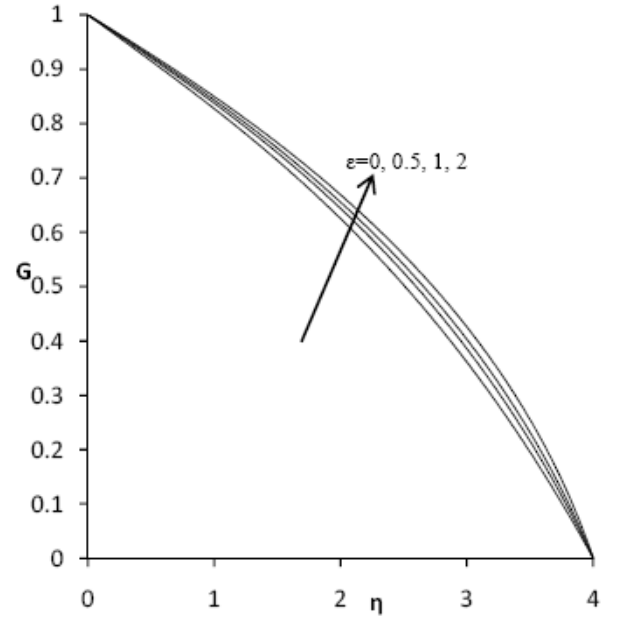

Fig. 3. Temperature profile with $\varepsilon\left(\operatorname{Pr}=0.7, \mathrm{k}_{\mathrm{c}}=1, \mathrm{Sc}=2\right.$, $\mathrm{N}=1, \lambda=1)$

From Figs. 4 and 5 effect of buoyancy parameter due to thermal diffusion $(\lambda)$ on velocity, temperature and concentration have been presented which shows that the magnitude of velocity, temperature and concentration decreases with increasing values of $\lambda$.

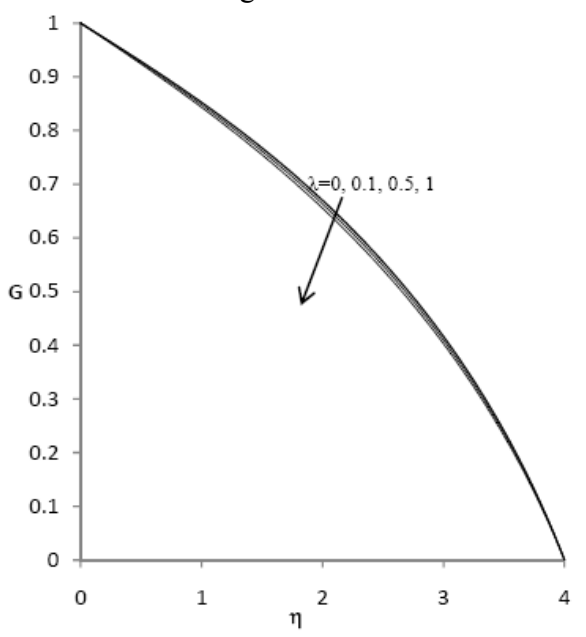

Fig. 4. Velocity Profile with $\lambda\left(\operatorname{Pr}=0.7, \mathrm{k}_{\mathrm{c}}=1, \varepsilon=1\right.$, $\mathrm{N}=1, \mathrm{Sc}=2$ )

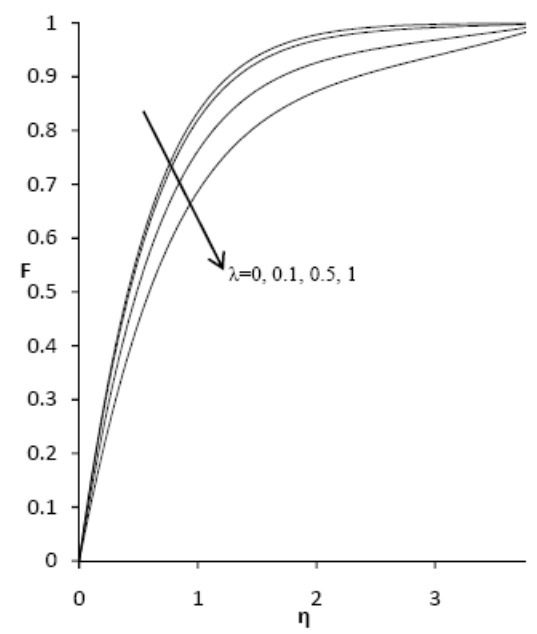

Fig. 5. Temperature Profile with $\lambda\left(\operatorname{Pr}=0.7, \mathrm{k}_{\mathrm{c}}=1, \varepsilon=1\right.$, $\mathrm{N}=1, \mathrm{Sc}=2$ )
In Figs. 7 and 8 it have been seen that concentration decreases and velocity increases with increasing values of $\mathrm{k}_{\mathrm{c}}$.

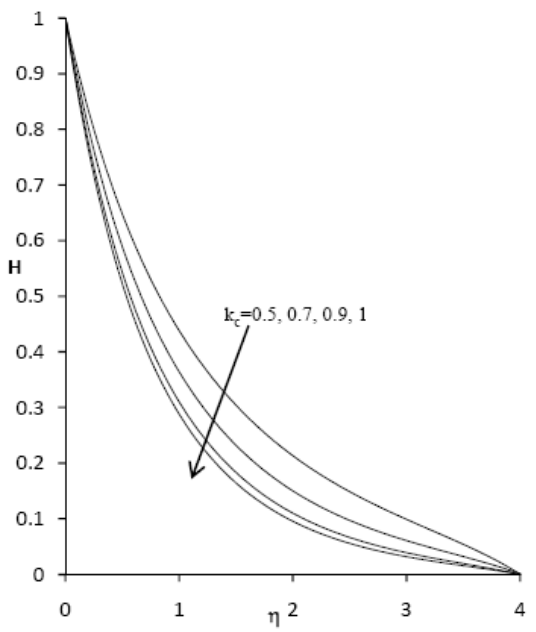

Fig. 7. Concentration Profile with $\mathrm{k}_{\mathrm{c}}(\operatorname{Pr}=0.7, \lambda=1, \varepsilon=1$, $\mathrm{N}=1, \mathrm{Sc}=2$ )

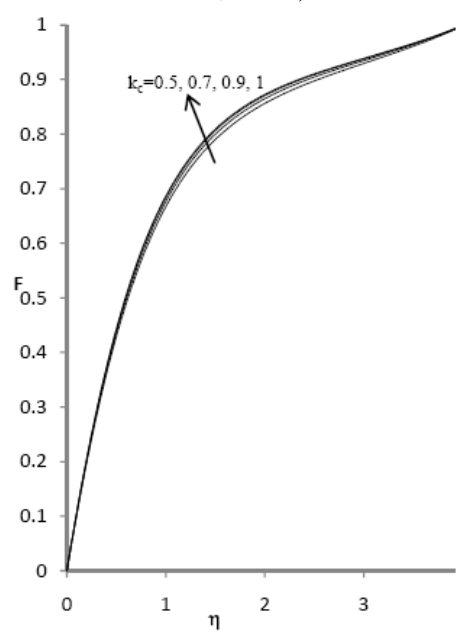

Fig. 8. Velocity Profile with $\mathrm{k}_{\mathrm{c}}(\operatorname{Pr}=0.7, \lambda=1, \varepsilon=1, \mathrm{~N}=1$, $\mathrm{Sc}=2$ )

Finally Fig. 9 presents the effect of $\mathrm{N}$ on velocity and shows that velocity decreases with increasing values of $\mathrm{N}$.

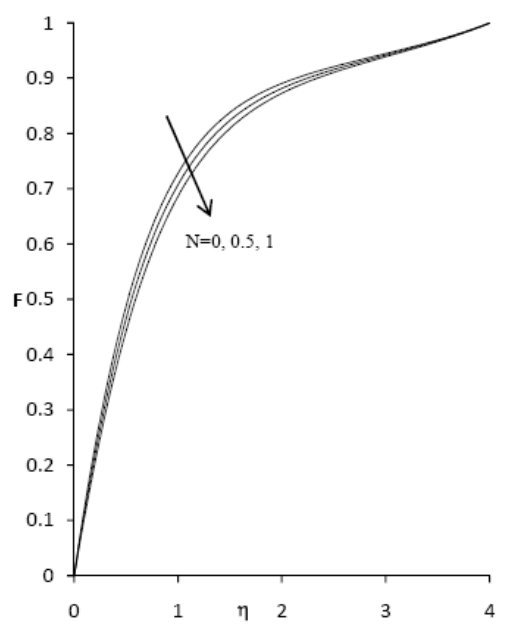

Fig. 9. Velocity Profile with $\mathrm{N}\left(\operatorname{Pr}=0.7, \lambda=1, \varepsilon=1, \mathrm{k}_{\mathrm{c}}=1\right.$, $\mathrm{Sc}=2$ ) 
The effects of $\varepsilon$ and $\mathrm{Sc}$ on skin friction parameter $\left(\mathrm{F}^{\prime}{ }_{\mathrm{w}}\right)$, heat transfer rate $\left(\mathrm{G}_{\mathrm{w}}^{\prime}\right)$ and mass transfer rate $\left(\mathrm{H}^{\prime}{ }_{\mathrm{w}}\right)$ have been presented in Table 1. Magnitude of skin friction parameter and mass transfer rate increases but magnitude of heat transfer rate decreases with increasing values of both the parameters $\varepsilon$ and Sc.

Table 1 Effect of variation of thermal conductivity parameter $(\varepsilon)$ and Schmidt Number $(\mathrm{Sc})$ on skin friction $\left(\mathrm{F}_{\mathrm{w}}^{\prime}\right)$, heat transfer rate $\left(\mathrm{G}_{\mathrm{w}}^{\prime}\right)$ and mass transfer rate $\left(\mathrm{H}^{\prime}{ }_{\mathrm{w}}\right)$

\begin{tabular}{|c|c|c|c|}
\hline \multicolumn{4}{|c|}{$\mathrm{Ge}=2, \operatorname{Pr}=0.7, \mathrm{k}_{\mathrm{c}}=1, \mathrm{Sc}=2, \mathrm{~N}=1, \lambda=1$} \\
\hline$\varepsilon$ & $\mathrm{F}_{\mathrm{w}}^{\prime}$ & $\mathrm{G}_{\mathrm{w}}^{\prime}$ & $\mathrm{H}_{\mathrm{w}}^{\prime}$ \\
\hline 0 & 1.110459 & -0.168999 & -1.350554 \\
\hline 0.5 & 1.110984 & -0.155870 & -1.350803 \\
\hline 1 & 1.111249 & -0.149030 & -1.350943 \\
\hline 2 & 1.111519 & -0.141844 & -1.351100 \\
\hline \multicolumn{4}{|c|}{$\mathrm{Ge}=2, \mathrm{Pr}=0.7, \mathrm{k}_{\mathrm{c}}=1, \varepsilon=1, \mathrm{~N}=1, \lambda=1$} \\
\hline $\mathrm{Sc}$ & $\mathrm{F}_{\mathrm{W}}^{\prime}$ & $\mathrm{G}_{\mathrm{w}}$ & $\mathrm{H}_{\mathrm{w}}^{\prime}$ \\
\hline 0.7 & 1.085171 & -0.153780 & -0.955220 \\
\hline 1 & 1.085299 & -0.149950 & -0.955289 \\
\hline 1.5 & 1.100199 & -0.1493950 & -1.169366 \\
\hline 2 & 1.111249 & -0.1350943 & -1.1350943 \\
\hline
\end{tabular}

Table 2 shows the effects of $\mathrm{k}_{\mathrm{c}}$ and $\lambda$ on $\mathrm{F}^{\prime}{ }_{\mathrm{w}}, \mathrm{G}^{\prime}{ }_{\mathrm{w}}$ and $\mathrm{H}_{\mathrm{w}}^{\prime}$. This table shows that magnitude of skin friction parameter and mass transfer rate increases but magnitude of heat transfer rate decreases with increasing values of $k_{c}$. Also with increasing values of $\lambda$, magnitude of skin friction parameter decreases while the magnitude of heat transfer rate and mass transfer rate increases.

Table 2 Effect of variation of chemical reaction parameter $\left(\mathrm{k}_{\mathrm{c}}\right)$ and mixed convection parameter $(\lambda)$ on skin friction $\left(\mathrm{F}_{\mathrm{w}}^{\prime}\right)$, heat transfer rate $\left(\mathrm{G}_{\mathrm{w}}^{\prime}\right)$ and mass transfer rate $\left(\mathrm{H}_{\mathrm{w}}^{\prime}\right)$

\begin{tabular}{|c|c|c|c|}
\hline \multicolumn{4}{|c|}{$\mathrm{Ge}=2, \mathrm{Pr}=0.7, \varepsilon=1, \mathrm{Sc}=2, \mathrm{~N}=1, \lambda=1$} \\
\hline $\mathrm{k}_{\mathrm{c}}$ & $\mathrm{F}_{\mathrm{w}}^{\prime}$ & $\mathrm{G}_{\mathrm{w}}^{\prime}$ & $\mathrm{H}_{\mathrm{w}}^{\prime}$ \\
\hline 0.3 & 1.057370 & -0.15137 & -0.674210 \\
\hline 0.5 & 1.079306 & -0.15034 & -0.914130 \\
\hline 0.7 & 1.094650 & -0.14962 & -1.108300 \\
\hline 1 & 1.111249 & -0.14903 & -1.350943 \\
\hline \multicolumn{4}{|c|}{$\mathrm{Ge}=2, \operatorname{Pr}=0.7, \mathrm{k}_{\mathrm{c}}=1, \mathrm{Sc}=2, \varepsilon=1, \mathrm{~N}=1$} \\
\hline$\lambda$ & $\mathrm{F}_{\mathrm{w}}^{\prime}$ & $\mathrm{G}_{\mathrm{w}}^{\prime}$ & $\mathrm{H}_{\mathrm{w}}^{\prime}$ \\
\hline 0 & 1.573891 & -0.139190 & -1.315756 \\
\hline 0.1 & 1.528603 & -0.140132 & -1.319459 \\
\hline 0.5 & 1.345375 & -0.144170 & -1.333889 \\
\hline 1 & 1.111249 & -0.149030 & -1.350943 \\
\hline
\end{tabular}

Table 3 represents the values of $\mathrm{F}^{\prime}{ }_{\mathrm{w}}, \mathrm{G}^{\prime}{ }_{\mathrm{w}}$ and $\mathrm{H}_{\mathrm{w}}{ }_{\mathrm{w}}$ with buoyancy parameter $(\mathrm{N})$. This table shows that magnitudes of $\mathrm{F}_{\mathrm{w}}^{\prime}, \mathrm{G}_{\mathrm{w}}^{\prime}$ and $\mathrm{H}_{\mathrm{w}}^{\prime}$ increases with increasing value of $\mathrm{N}$.

\section{ACKNOWLEDGEMENTS}

The authors are thankful to the referees for their valuable comments.
Table 3 Effect of variation of buoyancy parameter $(\mathrm{N})$ on skin friction $\left(F_{\mathrm{W}}^{\prime}\right)$, heat transfer rate $\left(G_{\mathrm{w}}^{\prime}\right)$ and mass transfer rate $\left(\mathrm{H}_{\mathrm{w}}^{\prime}\right)$

\begin{tabular}{|c|c|c|c|}
\hline \multicolumn{4}{|c|}{$\mathrm{Ge}=2, \mathrm{Pr}=0.7, \varepsilon=1, \mathrm{Sc}=2, \mathrm{k}_{\mathrm{c}}=1, \lambda=1$} \\
\hline $\mathrm{N}$ & $\mathrm{F}_{\mathrm{w}}^{\prime}$ & $\mathrm{G}_{\mathrm{w}}^{\prime}$ & $\mathrm{H}_{\mathrm{w}}^{\prime}$ \\
\hline 0 & 1.2946590 & -0.146890 & -1.340340 \\
0.5 & 1.1203112 & -0.147979 & -1.345730 \\
0.9 & 1.1296490 & -0.148809 & -1.349917 \\
1.0 & 1.1112490 & -0.149030 & -0.1350943 \\
\hline
\end{tabular}

\section{REFERENCES}

Ackerberg, R.C. (1965). The viscous incompressible flow inside a cone, J. Fluid Mech. 21, 47-81.

Eswara, A.T. and B.C. Bommaiah (2004). The effect of variable viscosity on laminar flow due to a point sink, Indian J. Pure Applied Math., 35(6), 811815 .

Eswara, A.T., S. Roy and G. Nath (2000). Unsteady MHD forced flow due to a point sink. Acta Mechanica 145, 159-172.

Ibrahim, F.S., A.M. Elaiw and A.A. Bakr (2008). Effect of chemical reaction and radiation absorption on the unsteady MHD free convection flow past a semi infinite vertical permeable moving plate with heat source and suction. Communication $s$ in Nonlinear science and Numerical simulation 13, 1056-1066.

Mahanti, N.C. and P. Gaur (2009). Effects of varying viscosity and thermal conductivity on steady free convective flow and heat transfer along an isothermal vertical plate in the presence of heat sink. Journal of Applied Fluid Mechanics 2(1), 2328.

Muthucumaraswamy, R. (2002). Effects of chemical reaction on a moving vertical isothermal surface with suction. Acta Mechanica 155, 65-70.

Roseanhead, L. Laminar Boundary Layer. (1963). Oxford University Press, Oxford.

Seddeek, M. A. and A. M. Salem (2005). Laminar mixed convection adjacent to vertical continuously stretching sheet with variable viscosity and variable thermal diffusivity. Heat and Mass Transfer 41, 1048-1055.

Sharma, P. R. and G. Singh (2008). Effects of variable thermal conductivity and heat source/sink on MHD flow near a stagnation point on a linearly stretching sheet. Journal of Applied fluid mechanics 2(1), 13-21.

Schlichting, H. Boundary Layer Theory. (1979). McGraw Hill, New York.

Takhar, H. S., C. D. Surma Devi and G. Nath (1986). MHD flow with heat and mass transfer due to a point sink. Indian J. Pure Applied Math 17(10), $1242-1247$ 